\title{
Rethinking of the Chinese Approach to Physician Apology Legislation: From the Legislative Dilemma of Transplantation
}

\author{
Xueting Liang, Lei Feng* \\ School of Public Health and Management, Chongqing Medical University, Chongqing Research Center for Medical and Social \\ Development, Collaborative Innovation Center for Social Risk Prediction and Governance in the Health Field, Chongqing, China \\ Email: *xuetingliang123@126.com
}

How to cite this paper: Liang, X. T. and Feng, L. (2020) Rethinking of the Chinese Approach to Physician Apology Legislation: From the Legislative Dilemma of Transplantation. Open Journal of Medical Psychology, 9, 70-78.

https://doi.org/10.4236/ojmp.2020.92006

Received: March 26, 2020

Accepted: April 27, 2020

Published: April 30, 2020

Copyright $\odot 2020$ by author(s) and Scientific Research Publishing Inc. This work is licensed under the Creative Commons Attribution International License (CC BY 4.0).

http://creativecommons.org/licenses/by/4.0/

\begin{abstract}
Physician apology legislation has gradually become a new legislative measure to resolve medical conflicts and repair doctor-patient relationship in many countries outside the region. In almost all cases using voice, to calm analysis found that the legislation of our country doctors apologize transplantation may face an apology from responsibility way to large span, dispute resolution mechanism from the free will to the legislative mandate disorders significantly, from general to special legislation difficulties facing a predicament, and make an apology may make doctors in passive in the moral, intensifies the doctor-patient conflicts, etc. In order to resolve the dilemma and establish a physician apology system adapted to China's national conditions, we should weaken the concept of apology liability through education, incorporate the elements of apology into the mediation mechanism of medical disputes, take the regulations on prevention and handling of medical disputes as a legislative breakthrough, and widely implement the patient safety system.
\end{abstract}

\section{Keywords}

Medical Disputes, Apology Law, Legislation, Transplant Reference

\section{Introduction}

\section{Problem Statement}

In the 1970s, with the rapid development of the medical insurance industry in the United States and the substantial increase in the amount of compensation for medical negligence, the number of medical litigation cases increased sharply [1]. In order to solve practical problems such as the increasing doctor-patient con- 
flicts and the decreasing doctor-patient trust, American states began to explore the establishment of a legal system of physician apology. In 1986, Massachusetts law first proposed the "safe-harbor" principle [2], which provides legal protection for apologies. Then 38 states, including Texas, followed suit, encouraging physicians to apologize to patients and their families. According to the differences in the scope of the protection of the physician's apology contents in different states, it is divided into two modes: partial apology and full apology. A "Full Apology" is an expression of sympathy, regret, or acknowledgment of errors, responsibilities, and mistakes in a medical practice that is protected by law and cannot be used as evidence in a court of law. It is generally believed that whether a partial apology or a full apology is implemented, it can ease the antagonism of patients, promote the effective communication between doctors and patients, and thus reduce the amount of medical litigation, reduce the amount of compensation, strengthen the doctor-patient trust and repair the doctor-patient relationship. Under this influence, 56 countries and regions [3], such as Canada, Australia and the United Kingdom, have enacted apology legislation successively and achieved remarkable results. China's Hong Kong and Taiwan regions have also put apology legislation on the agenda. It can be seen that the apology system of doctors has attracted great attention all over the world.

In view of the tense doctor-patient relationship in China and the current situation of medical conflicts, scholars hold a positive attitude towards the legislation of doctors' apology and put forward positive ideas for reference. Chen yunliang [4], Yan ying [5] and others suggested that the physician apology system should be included in the basic medical health and health promotion law (draft), and a complete apology mechanism should be set up to eliminate the evasive effect of physician apology, thus fundamentally reversing the situation that doctors dare not communicate honestly with patients. Manhongjie [6] suggested that a physician apology system should be established from four aspects: improving the supporting rules and regulations, establishing the evidence exclusion effect of apology, improving the reporting system of medical negligence with patient safety as the core, including medical adverse consequences into the scope of informed consent of patients, and establishing a non-litigation dispute resolution mechanism based on apology and communication. However, it is a pity that the scholars' research has not had a substantial impact on the legislative and practical fields, and such indifference also reflects the public's doubts on the feasibility and effect of the physician apology system.

Based on this, this article intends to analyze the practical dilemma of the transplantation and reference of the legal system of physician apology, and put forward the possible system reference approach, in order to provide a new perspective for the reform and improvement of the medical dispute resolution mechanism in China.

\section{The Dilemma at the Normative Level}

Legal coordination means the integration of legal concepts and the unification of 
legal functions, and it is a necessary condition for the smooth operation of legal system. If we want to learn from the transplant doctor apology legal system, we should carefully consider the coordination with the existing law.

\subsection{The Large Span from Liability Law to Dispute Resolution Mechanism}

Apology is widely used in China's legal field as a way of taking responsibility. In 1980, the Criminal Procedure Law of the People's Republic of China upgraded apology to legal responsibility for the first time. Article 32 of the Law stipulates that criminal sanctions may be dispensed with if the circumstances of a crime are minor and no penalty is required. However, depending on the circumstances of the case, a reprimand or an order to repent, make an apology or compensate for losses may be given, or administrative sanctions may be imposed by the competent authorities. In 1987, the General Principles of the Civil Law of the People's Republic of China incorporated apology into the law and clearly defined apology as a statutory way of bearing civil liability. Since then, China's laws have inherited the above provisions. For example, Article 15 of the Tort Liability Law stipulates that "apology for tribute is one of the ways to bear liability for torts". From this, we can see that in China's legislation, apology is a legal responsibility, with punishment and vigilance.

However, in the extraterritorial physician apology act, physician apology is only a way to resolve pre-litigation medical disputes, and there is no inevitable connection between apology and responsibility, that is, the direct purpose of physician apology is to provide pre-litigation settlement through a non-litigation dispute mediation mechanism. and whether the act of apology can resolve disputes is not within the scope of the physician's consideration. In addition, in order to prevent doctors from apologizing as a way of assuming responsibility, American States have formulated evidence rules to explicitly exclude the apology words and actions of doctors and their institutions as evidence in court. Therefore, some scholars believe that as a way of accountability, apology is more of a non-criminal punishment, which has no real impact on the alleviation of doctor-patient contradiction but highlights the limitations of apology [7].

\subsection{Obstacles Obvious From Free Will to Legislative Mandatory Requirements}

Existing research shows that the extraterritorial legislation, represented by the United States, mainly cuts off the link between apology and adverse evidence, which makes the apology of doctors initiative and voluntary, while as a way of assuming responsibility, the apology of our legislation is mandatory [5]. However, through the induction and collation of foreign literature, it is found that in the 38 States that have implemented the physician apology system in the United States, some states have specific provisions on the time of apology, and apologies beyond the legal time limit will no longer be protected by law. For example, 
Vermont requires medical institutions and their employees to make an apology within 30 days of knowing or ought to know that a medical error has occurred, Illinois only protects apologies made within 72 hours, and South Carolina requires apologies to be raised in a meeting to discuss adverse consequences [8]. On the one hand, in order to encourage doctors to apologize, the government adopts legislative forms to protect doctors' apology words and deeds from evidential effect, but on the other hand, it indirectly forces doctors to apologize by stipulating the time limit for apology. Except for the above States, the other States do not specify the time of apology, but from the legislative trend, the separate legislation of apology for doctors itself is to use the law to promote doctors to issue apologies, missing this opportunity will be detrimental to future litigation. It can be seen that the apology of extraterritorial doctors is a legal obligation and legally compulsory.

In contrast, in China's existing laws apologies from various actors other than the way of responsibility are an expression of free will. However, in order to encourage the free expression of apologies, China has provided an exemption incentive mechanism from the legal level, for example, Article 67 of the "Several Provisions of the Supreme People's Court on Evidence in Civil Proceedings" states that "In litigation, Or the recognition of the facts of the case involved in the compromise for the purpose of settlement shall not be used as evidence against it in subsequent proceedings. "In this provision, "recognition" in "recognition of the facts of the case" also includes admission of one's own mistakes and expression of apology, which is consistent with the content of a full apology. Based on this, some scholars believe that the view that there is no apology exemption legislation in China's existing legal provisions should be denied. However, the essence of this clause is still to encourage rather than force apologies.

\subsection{Facing Difficulties from Universal Legislation to Separate Legislation}

The application of the American Apology Act is limited to medical adverse events, and the evidence rules of various States also clearly point out that only when the subject of apology is a doctor or a medical institution will their apology be protected by law. It can be seen that the apology system is a special legislative regulation for the special industry of medical treatment. In China, there is no special legislation on apology in medical professional legislation, but apology as a way of responsibility taking is more common in the legislation. If the apology legislation is enacted separately to the physician group, especially to exempt them from the adverse evidence effect and fault liability effect, it may have an impact on the existing legislative structure. In other words, the special protection of physician groups is neither supported by sufficient legislative reasons, nor echoed in the legislative structure, and the hasty implementation of a single legislation leads to doubts about the legal privileges of physicians. 


\section{Dilemmas Faced in Real Situations}

\subsection{Apologies May be Morally Passive}

French scholar Legrand proposed the "cultural barrier theory" [9]. He believes that the content of law depends on culture, and the understanding of legal meaning will be different due to the different cultures of different countries, that is to say, the cultural differences between countries will cause insurmountable obstacles to legal transplantation [10]. American scholar Giltz points out that law has the property of "local knowledge" [11]. As mentioned above, although the Apology Act does not explicitly explain and define the word "apology", it is not difficult to see from its legal provisions that apologies are closely related to words of sympathy such as "sympathy", "compassion", "mourning" and has no causal relationship with the negligence of the apologizer's behavior, rather than a compensatory or compensatory act made by the apologizer out of guilt. For example, Massachusetts stipulates that an "apology" is an act of condolences, written or tribute to the victims or family members of the accident in expressing sympathy or general concern about the pain or death caused by the accident. The "Modern Chinese Dictionary" of China defines "apology" as an apology for doing something wrong, and emphasizes that the premise of an apology is that the apology person has acted improperly. Therefore, in general cognition, we have formed the thinking mode that apology is equal to confession. It can be seen that different cultural traditions between the East and the West lead to different perceptions of apology. For American physicians, apology is a strategic tool for medical reconciliation, and its legal significance is greater than its moral significance. But for Chinese doctors, the apology may be regarded as a remorse after a loss, making it morally passive. Therefore, based on the moral significance of an apology, doctors will not easily choose to apologize.

In addition, China is a typical "acquaintance society". People pay great attention to "face" in interpersonal communication. According to a survey by Aaorn lazare, even in the modern Chinese society, people still clearly express the importance of face to them as high as $85 \%$ [12]. Zhai Xuewei's research [13] also shows that "face" is highly correlated with concepts such as shame, honor, shame, and fame, and an apology necessarily involves the "face" of the perpetrator. From ancient times to the present, society has given physicians positive images such as "doctor's benevolence". Under these auras, physicians have often become moral models or positive models of society. Therefore, morally Negligence appears to be particularly "losing face", and this psychological gap has led physicians to be reluctant to apologize. Therefore, even at the moment when the apology does not have evidence, doctors would rather give more money than apologize to the patient.

\subsection{Apology May Exacerbate Doctor-Patient Conflict}

According to empirical data from the Johns Hopkins Children's Center and the Veterans Affairs Medical Center in Lexington [6], physician apologies play an 
important role in reducing the rate of medical litigation, reducing the cost of medical compensation, and improving the rate of medical reconciliation. However, it is worth pondering if China's physician apology system can achieve the expected results? As Doug Wojcieszak notes, the most significant barrier to apology may "not be the 'outside world' of patients, lawyers, and courts, but the' inside culture' of hospitals and the medical community [14]. First, apologies in our daily lives are different from apologies in the medical field. In daily interpersonal communication, apologies are widely used on the premise that the impact of the dispute is small and the party's damage or loss is not large, so apology for commendation has become an important way to resolve daily disputes and ease interpersonal relationships. However, in the special field of medical treatment, the occurrence of doctor-patient disputes is based on the health damage or even death of the parties, and the loss is irreparable. In addition, the existing doctor-patient relationship is more tense, medical staff often feel like treading on thin ice, once the dispute arises, the apology of medical staff will be questioned by patients and their families, and further produce "why does the doctor apologize? Is he guilty?" Or "he apologized, he should be responsible and other suspicions." It can be seen that the doctor's apology after the dispute may not only fail to appease the patient's emotions, but will "fire on the fire".

Second, doctors fear that their apologies will be used against them in subsequent lawsuits. As mentioned above, although the existing law of our country excludes recognition of the case as favorable evidence, it has not yet explicitly used the word apology to clarify that apology words and deeds do not have an evidentiary effect, nor has it directly legislated for the effect of apology, so in practice, the apology behavior of the parties may affect the judge's discretion, making the actor at a disadvantage in litigation.

\section{China's Approach to Physician Apology Legislative Transplantation}

As mentioned earlier, the legislation of the doctor's apology system in China faces many difficulties, but it is undeniable that the medical apology system does have an irreplaceable role in doctor-patient disputes. Therefore, how to effectively introduce the doctor's apology system into China should be studied currently. For this reason, the following suggestions are made:

\subsection{Abandoning the "Blame" Culture and Strengthen Medical Ed- ucation to Promote Doctor-Patient Harmony}

The existing medical dispute resolution mechanism in China focuses on blame and compensation, which forces doctors to focus on how to effectively evade responsibility after disputes occur, rather than on the possibility of harmonious coexistence between doctors and patients in the future, often ignoring the emotional comfort of patients and their families, resulting in mutual hostility. If we want to break this deadlock, we can learn from foreign experience and start from medical education. First, we should increase the course of dispute resolution in 
medical education [15], and use practical teaching methods such as a case or role-playing to make them have professional knowledge and correct the imputation culture in medical culture, so as to establish the idea that apology is not terrible. Second, future doctors should be given special apology training in the standardized training of residents [16] [17]. Standardized training of residents is an important part of post-graduate medical education and an important step to effectively combine theoretical knowledge with practice. At present, the standardized training of physicians focuses on the training of clinical skills and neglects the cultivation of the comprehensive ability of doctors. In the process of physician apology training, trainers should explain the basic concepts, subjects and objects, time limit and forms of apology in detail, and require physicians to be familiar with and apply them. Furthermore, the training of doctors' communication skills should be strengthened during the training process to form a good "two-way" communication mechanism between doctors and patients.

\subsection{Incorporate Apology Elements into the Mediation Mechanism of Medical Disputes to Promote the Harmonious Development of Doctor-Patient Relationship}

Unlike the adversarial legal proceedings, the dispute mediation mechanism provides the parties with an opportunity for direct dialogue. At present, the mediation mechanism of non-litigation medical disputes in China mainly refers to the main people's mediation, but does not make corresponding provisions for the apology of doctors in the mediation process. Taiwan's "Medical Dispute Settlement and Medical Accident Compensation Act (Draft)" clearly stipulates that "Regrets, apologies, concessions or other statements made by medical institutions or medical personnel in the process of mediation to alleviate medical tension shall not be adopted as evidence or basis for adjudication in relevant proceedings."Therefore, we can draw lessons from the above provisions, exclude the evidence effect of doctor's apology in the process of mediation, and clarify the specific operation process of apology.

\subsection{Add a Special Clause to the "Regulations on the Prevention and Handling of Medical Disputes" to Provide a Legal Basis for Doctors to Apologize}

The Regulations on the Prevention and Handling of Medical Disputes (hereinafter referred to as the "Regulations") implemented in 2018 is an important legal basis for the treatment of medical disputes in China, which can be used as a breakthrough point for the legislation of physician apology. Article 4 of the "Regulations" stipulates: "To deal with medical disputes, we should follow the principle of fairness, impartiality and timeliness, seek truth from facts and deal with them according to law."Among them, the "principle of promptness" and "practical truth" are the theoretical basis of physician apology, which should be added to encourage physicians to apologize after disputes occur to promote the harmony of doctor-patient relationship. $t$ the same time, the concept, subject 
and object, time limit, form and legal effect of apology can be explained in detail in the Regulations.

\subsection{Implementation of Patient Safety System Such as Medical Adverse Event Reporting System}

In 2004, the World Health Organization (WTO) established the Global Alliance for Patient Safety to provide guidance for the development of patient safety work in various countries. In order to effectively promote patient safety, various supporting systems emerge as the times require. Take the widely recognized medical adverse event reporting system as an example. Adverse event reporting system enhances the transparency between doctors and patients, reverses the hostile mentality caused by high distrust between doctors and patients, and provides a basis for doctors to apologize through doctors' active disclosure of negligence in medical malpractice. The effective implementation of physician apology system also promotes physicians to dare to disclose adverse events. At present, many countries in Europe and the United States have established a national medical adverse event reporting system, in 1995, the Joint Committee on Accreditation of Medical Institutions in the United States established a medical adverse event reporting system [18], and in 2001, the British Patient Safety Agency established a medical adverse time reporting system [19]. Although there is also a patient safety reporting system in China, the development is still not perfect. The current literature on the implementation effect and use of medical negligence reports is small, indicating that the system has not yet attracted attention in the medical field, which has formed a certain psychological obstacle for physicians to apologize. In addition, the common purpose of the implementation of the hospital complaint reception system, the right to consent of patients and other measures and measures is to strengthen doctor-patient communication and build a harmonious doctor-patient relationship. The above-mentioned systems all promote the apology of physicians and should be widely implemented.

\section{Summary}

Compared with the United States, Canada and other countries, physician apology is still a relatively new concept in China, so there is relatively little research on this. Although international theories can provide some useful lessons, due to different national conditions, the relevant US systems and practices are relatively lacking in China. However, the legislative research on the doctor's apology system not only opens up new ideas and perspectives for the effective resolution mechanism of doctor-patient disputes, but also provides a reference for the harmonious development of the future doctor-patient relationship.

\section{Conflicts of Interest}

The authors declare no conflicts of interest regarding the publication of this paper. 


\section{References}

[1] Zhang, M. and Li, N. (2009) Enlightenment from American Medical Dispute Handling and Legislative Experience. Chinese Journal of Hospital Management, 25, 243-246.

[2] Lee, T. (2000) Apology Subverted: The Commodification of Apology. Yale Law Journal, 109, 1135-1160. https://doi.org/10.2307/797485

[3] Liu, X. (2017) Resolving Doctor-Patient Disputes Try to Legislate for an Apology. Health News, 2017-08-03 (006).

[4] Chen, Y.L. (2018) Thinking about Some Issues of the "Basic Medical and Health Promotion Law (Draft)". China Health Legal System, 26, 1-3 + 16.

[5] Yan, Y. (2017) Function and Legislative Enlightenment of Extraterritorial Apology System in Medical Dispute Resolution. Medicine and Philosophy $(A), 38,66-70$.

[6] Man, H.J. (2017) Development of Medical Apology Law and Medical Dispute Resolution Mechanism-American Experience and China's Approach. Contemporary Law, 31, 89-98.

[7] Hao, W.H. (2011) Comparative Analysis of Canada-China Apology Method. Comparative Law Research, No. 6, 65-74.

[8] Wang, L.S. (2014) Studies on American Physician Apology System and Its Impact on Evidence Law. Evidence Science, 22, 750-759.

[9] Legrand, P. (1997) The Impossibility of "Legal Transplants". Maastricht Journal of European and Comparative Law, No. 4, 111-124. https://doi.org/10.1177/1023263X9700400202

[10] Chase, O. (1995) Cultural Dimensions in Civil Procedure. American Journal of Comparative Law, 45, 861-870. https://doi.org/10.2307/841023

[11] Giltz (2004) Local Knowledge: An Anthropological Essay Collection. Translated by Wang Hailong and Zhang Jiaxuan, Central Compilation and Translation Press, Beijing, 223, 255.

[12] Lazare, A. (1995) Go Ahead Say You're Sorry. Psychology Today, January-February.

[13] Zhai, X.W. (2016) Shame and Face: The Slightest Difference, the Most Lost. Studies in Sociology, 31, 1-25 + 242.

[14] Dresser, R. (2008) The Limits of Apology Laws. Hastings Center Report, 38, 6-7. https://doi.org/10.1353/hcr.0.0015

[15] Westrick, S.J. and Jacob, N. (2006) Disclosure of Errors and Apology: Law and Ethics. The Journal for Nurse Practitioners, 12, 120-126. https://doi.org/10.1016/j.nurpra.2015.10.007

[16] McMichael, B.J., Van Horn, R.L. and Viscusi, W.K. (2018) "Sorry" Is Never Enough: How State Apology Laws Fail to Reduce Medical Malpractice Liability Risk. https://ssrn.com/abstract=2883693

[17] Carroll, R., Allan, A. and Halsmith, M. (2017) Apologies, Mediation and the Law: Resolution of Civil Disputes. Oñati Socio-Legal Series, 7, 569-600. https://ssrn.com/abstract $=3029486$

[18] Li, Q.C. (2012) Light and Darkness in American Medicine. Translated by Xu Meng, Qiuzhen Publishing House, Beijing.

[19] Merry, A. and Smith, A.M. (2001) Errors, Medicine and the Law. Cambridge University Press, Cambridge, 286-295. 